\title{
REG3A overexpression suppresses gastric cancer cell invasion, proliferation and promotes apoptosis through PI3K/Akt signaling pathway
}

\author{
YAN-SONG QIU $^{1}$, GUANG-JUN LIAO ${ }^{2}$ and NING-NING JIANG ${ }^{2}$ \\ Departments of ${ }^{1}$ General Surgery and ${ }^{2}$ Bone Tumor, Yantai Shan Hospital, Yantai, Shandong 264000, P.R. China
}

Received December 13, 2016; Accepted February 6, 2018

DOI: $10.3892 /$ ijmm.2018.3520

\begin{abstract}
Gastric cancer (GC) is the second most common cause of cancer-related deaths. In recent years some essential factors for resolution were identified, but the clinical trials still lack the effective methods to treat or monitor the disease progression. Regenerating islet-derived $3 \alpha$ (REG3A) is a member of REG protein family. Previous studies have investigated the altered expression of REG3A in various cancers. In this investigtion we aimed at the biological function and the underlying molecular mechanism of REG3A in GC. We found that REG3A was significantly downregulated in GC and closely related with patient prognoses. REG3A overexpression suppressed the invasion and proliferation promoting apoptosis of GC cells. While REG3A knockdown promoted the invasion, and proliferation suppressing apoptosis of GC cells. It was further found that REG3A performed its biological functions mainly through phosphatidylinositol 3 kinase (PI3K)/ Akt-GSK3 $\beta$ signaling pathway axis. REG3A may be a promising therapeutic strategy for GC.
\end{abstract}

\section{Introduction}

Gastric cancer (GC) is a heterogeneous disease with two distinct morphological subtypes: gastric intestinal type adenocarcinoma and diffuse gastric adenocarcinoma. Intestinal and diffuse type GC show variable environmental aetiologies, clinical manifestation and genetic background (1,2). Diffuse gastric adenocarcinoma is often seen in female and young individuals, while the intestinal type adenocarcinoma is more often associated with intestinal metaplasia and Helicobacter pylori infection (3). Based on previous studies we know that frequent inactivating mutations in cell adhesion and chromatin remodelling genes exist in addition to TP53 mutations $(4,5)$. Although

Correspondence to: Dr Ning-Ning Jiang, Department of Bone Tumor, Yantai Shan Hospital, Yantai Shan Hospital, 91 Jiefang Road, Zhifu, Yantai, Shandong 264000, P.R. China

E-mail: nnjiang@sohu.com

Key words: regenerating islet-derived $3 \alpha$, gastric cancer, invasion, apoptosis, proliferation, phosphatidylinositol 3 kinase/Akt some essential factors for resolution were identified in recent years, the clinical trials still lack effective methods to treat the disease and reliable biomarkers to monitor its progression (6-9).

Regenerating islet-derived $3 \alpha$ (REG3A) is a member of REG protein family and also named as human hepatocarcinomaintestine-pancreas (HIP) or human pancreatitis-associated protein (PAP) (10-12). REG3A is a secreted calcium-dependent lectin protein which is related with pancreatic islet cell regeneration, pancreatic stellate cell activation (PSCs) $(13,14)$ and liver regeneration (15). It has been reported that REG3A plays important roles in a number of human cancers, including GC (16), pancreatic cancer (17-19) and colorectal cancer (20). REG3A also regulates keratinocyte proliferation and differentiation after skin injury (21). However, the exact function of REG3A on GC and the details of the pathways has not been demonstrated.

In this study, we showed that the expression of REG3A was significantly downregulated in GC and closely related with patient prognoses. REG3A could regulate the invasion, proliferation and apoptosis of GC cells through phosphatidylinositol 3 kinase (PI3K)/Akt-GSK3 $\beta$ signaling pathway axis.

\section{Materials and methods}

Cell culture. Human GC cell lines, including AGS, BGC-823, HGC-27, MGC-803, MKN-45 and SGC-7901 were purchased from Cell Bank of the Chinese Academy of Sciences. Cells were cultured in RPMI-1640 medium supplemented with $10 \%(\mathrm{v} / \mathrm{v})$ fetal calf serum and $1 \%$ antibiotics at $37^{\circ} \mathrm{C}$ in a humidified incubator under $5 \% \mathrm{CO}_{2}$ condition.

Clinical samples. Human gastric tumor (19 cases) and normal tissues (15 cases) were obtained from Department of Bone Tumor, Yantai Mountain Hospital. All human materials were obtained with informed consent, and protocols were approved by the ethics review committee of the World Health Organization Collaborating Center for Research in Human Production.

Data mining using TCGA and GEO. REG3A gene expression were analyzed using microarray gene expression datasets deposited in GEO database. A combined filter was applied to display the corresponding datasets. The cancer type was defined as GC and data type was mRNA, and analysis type 
was cancer versus normal analysis. The expression levels of REG3A gene were read from the displayed bar chart and these data were analyzed by Excel. Further, the gene expression data for GC was downloaded from TCGA. The RNA-seq gene expression data contain $\log _{2}$-transformed RNA-seq by expectation maximization (RSEM) values summarized at gene level.

Quantitative real-time PCR. Total RNA was extracted using TRIzol reagent, and reverse transcribed through PrimeScript RT-PCR kit (Takara, Dalian, China) according to the protocol. Real-time PCR analyses were performed with SYBR Premix Ex Taq (Takara) on a 7300 Real-time PCR system (Applied Biosystems, Waltham, MA, USA) at the recommended thermal cycling settings: one initial cycle at $95^{\circ} \mathrm{C}$ for $30 \mathrm{sec}$ followed by 40 cycles of $5 \mathrm{sec}$ at $95^{\circ} \mathrm{C}$ and $31 \mathrm{sec}$ at $60^{\circ} \mathrm{C}$.

Western blotting. Cells were lysed in lysis buffer. Proteins were separated by sodium dodecyl sulfate-polyacrylamide gel electrophoresis (SDS-PAGE) under reducing condition, followed by blocking in phosphate-buffered saline (PBS)/Tween-20 containing $1 \%$ BSA. The membrane was incubated with antibodies for REG3A (Abcam, Cambridge, MA, USA), phospho-Akt, total-Akt, phospho-GSK3 $\beta$, total-GSK3 $\beta$ (all from Cell Signaling Technology, Beverly, MA, USA), glyceraldehyde 3-phosphate dehydrogenase (GAPDH) (Sigma, St. Louis, MO, USA) and species-specific secondary antibodies. Bound secondary antibodies were revealed by Odyssey imaging system (LI-COR Biosciences, Lincoln, NE, USA).

Lentivirus production and cell transduction. Virus packaging was performed in $293 \mathrm{~T}$ cells after cotransfection of pEZ-lv105 vector (GeneCopoeia, Guangzhou, China) using Lipofectamine 2000 (Invitrogen, Carlsbad, CA, USA). Viruses were harvested at 48 and $72 \mathrm{~h}$ after transfection, and virus titers were determined. Target cells $\left(1 \times 10^{5}\right)$, including MGC-803 and BGC-823 cells, were infected with $1 \times 10^{6}$ recombinant lentivirus-transducing units in the presence of $6 \mu \mathrm{g} / \mathrm{ml}$ polybrene (Sigma).

siRNA transfection. Small interfering RNA duplexes for REG3A was produced by GenePharma (Shanghai, China). Transfection steps followed the manufacturer's protocols.

Invasion assays. MGC-803 and BGC-823 cells were detached and resuspended in serum-free DMEM. Approximately $2 \times 10^{4}$ cells in $0.1 \mathrm{ml}$ were placed in Matrigel (BD Biosciences, Bedford, MA, USA)-coated inserts (Millipore, Billerica, MA, USA) on the 24-well plate. DMEM containing 5\% (v/v) fetal bovine serum (FBS) was added to the bottom chamber. Cells were incubated at $37^{\circ} \mathrm{C}$ and allowed to invade through Matrigel for $48 \mathrm{~h}$. After incubation, filters were fixed and stained with $0.1 \%(\mathrm{w} / \mathrm{v})$ crystal violet. Non-invading cells were removed using a cotton swab while invading cells on the underside of the filter were counted under a microscope at a magnification, x200 or x400. At least five grids per field were counted and the experiments were repeated at least twice.

Apoptosis assays. Per well $5 \times 10^{5}$ cells were cultured on 12-well plates and serum starved for $48 \mathrm{~h}$ at $37^{\circ} \mathrm{C}$ in a $5 \% \mathrm{CO}_{2}$ atmosphere. After incubation, adherent cells were detached with $0.25 \%$ trypsin/0.01\% EDTA in $1 \mathrm{X}$ PBS. Detached and suspended cells were harvested in complete DMEM medium and centrifuged at 1,000 rpm for $5 \mathrm{~min}$. Each of the cells were washed with $1 \mathrm{X}$ PBS and stained with $100 \mu \mathrm{l}$ binding buffer containing $3.5 \mu \mathrm{l}$ Annexin $\mathrm{V}$ and $3.5 \mu \mathrm{l}$ propidium iodide (PI). Cells were incubated at room temperature for $15 \mathrm{~min}$ and analyzed by flow cytometry (BD Biosciences).

Statistical analysis. Data are presented as the means \pm standard error of the mean (SEM). Statistical analyses were performed using SPSS 16.0 for windows (IBM, Chicago, IL, USA). Cumulative survival time was calculated by the Kaplan-Meier method and analyzed by the log-rank test. The Chi-square test, and Student's t-test were used for comparison between groups. Values of $\mathrm{P}<0.05$ were considered statistically significant.

\section{Results}

REG3A expression is downregulated in GC tissues and closely related with patient prognoses. To determine the expression of REG3A in GC, we analyzed the microarray data from TCGA or GEO datasets. The TCGA dataset showed that the expression level of REG3A was significantly downregulated in GC tissues, compared with normal tissues (Fig. 1A). Further, we collected 19 cases of gastric tumor and 15 cases of normal tissues. By quantitative real-time PCR, we found that the expression level of REG3A was significantly downregulated in GC tissues (Fig. 1B).

It was further proven in GSE13911 and GSE13861 datasets, in which REG3A expression was downregulated in gastric intestinal type adenocarcinoma or diffuse gastric adenocarcinoma respectively (Fig. 1C-E). We also analyzed the data from KMplot. REG3A expression was closely related with patient prognoses. High REG3A expression was associated with improved overall survival (OS) $(\mathrm{P}=0.004)$ or disease-free survival (DFS) $(\mathrm{P}=0.038)$ (Fig. $1 \mathrm{~F}$ and $\mathrm{G})$.

Overexpression of REG3A in GC cells. To further investigate the role of REG3A in GC, we first detected the expression level of REG3A in six GC cell lines. As shown in Fig. 2A, we found that REG3A had low expression levels in MGC-803 and BGC- 823 cells. We established stable cell lines transduced by the lentivirus carrying the REG3A gene, designated as Lenti-REG3A, in MGC-803 and BGC-823 cells. The results from real-time PCR and western blotting showed that REG3A was overexpressed in both MGC-803 (Fig. 2B and D) and BGC-823 cells (Fig. 2C and E).

Overexpression of REG3A reduces the invasion and proliferation of GC cells, while increases the apoptosis of GC cells. We first investigated the role of REG3A in the invasion and apoptosis of GC cells. By Transwell Matrigel invasion assay, we found that REG3A overexpression reduced invasiveness of MGC-803 and BGC-823 cells after $48 \mathrm{~h}$ (Fig. 3A and C). Moreover, we found that apoptosis of GC cells was affected by overexpression of REG3A. Apoptosis of GC cells was determined by flow cytometry after the cells were serum starved for $48 \mathrm{~h}$. The results showed that the apoptosis rate was increased by the overexpression of REG3A in MGC-803 and BGC-823 cells (Fig. 3B and D). 

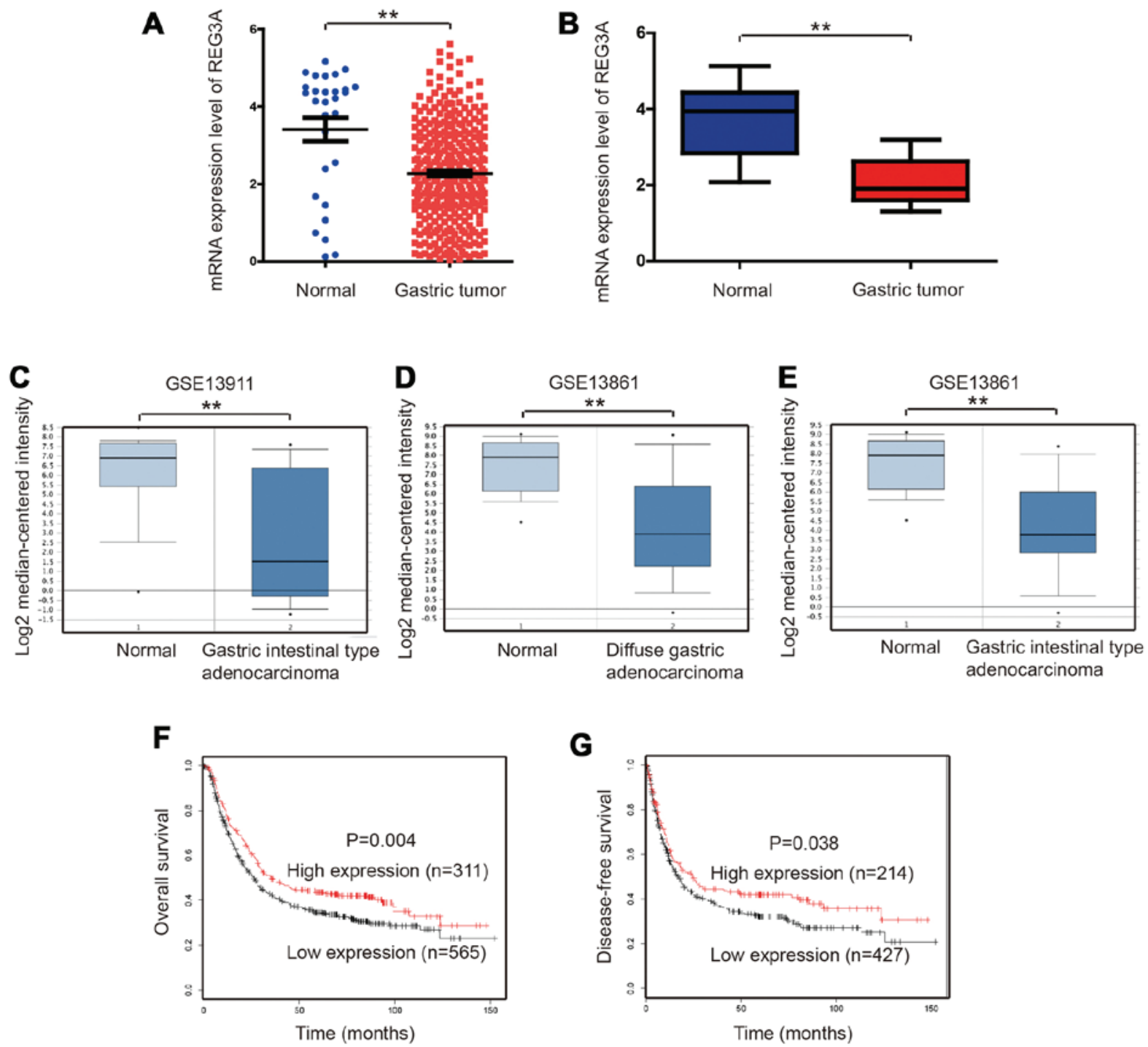

Figure 1. Regenerating islet-derived $3 \alpha$ (REG3A) is downregulated in gastric cancer (GC) tissues and closely related with patient prognoses. (A) The mRNA expression level of REG3A in GC and normal tissues. The data was obtained from TCGA dataset. (B) The mRNA expression level of REG3A in 19 cases gastric tumor and 15 casesof normal tissues. (C) The mRNA expression level of REG3A in gastric intestinal type adenocarcinoma and normal tissues. The data was obtained from GSE13911. (D and E) The mRNA expression level of REG3A in diffuse gastric adenocarcinoma (D) or gastric intestinal type adenocarcinoma tissues (E), compared with normal tissues. The data was obtained from GSE13861. ${ }^{* *} \mathrm{P}<0.01$. (F) Kaplan-Meier analysis of overall survival (OS) for the expression of REG3A. P=0.004. (G) Kaplan-Meier analysis of disease-free survival (DFS) for the expression of REG3A. P=0.038.

We further investigated the proliferation of GC cells after REG3A overexpression by cell counting kit-8 (CCK-8) proliferation assay. It was found that the proliferation of MGC-803 or BGC-823 cells was significantly reduced by REG3A overexpression at 24, 48 and $72 \mathrm{~h}$ time-points (Fig. 3E and F).

Knockdown of REG3A promotes the invasion and proliferation of GC cells, while suppresses apoptosis of GC cells. LMO3 had relative high expression levels in HGC-27 and SGC-7901 cells (Fig. 2A). So we selected HGC-27 and SGC-7901 cells and knocked out REG3A by using siRNA (labeled as si-REG3A-1 and si-REG3A-2). Through real-time PCR and western blotting analysis we found that REG3A was successfully silenced in HGC-27 (Fig. 4A and C) and SGC-7901 cells (Fig. 4B and D).

By Transwell Matrigel invasion assay and flow cytometry analysis, we found that knockdown of REG3A promoted the invasiveness and suppressed the apoptosis of HGC-27 (Fig. 4E) and SGC-7901 (Fig. 4F) cells after 48 h. Further, by CCK-8 cell viability assay, we found that the cell viability of HGC-27 and SGC-7901 cells was significantly increased by knockdown of REG3A at 24, 48 and $72 \mathrm{~h}$ time-points respectively (Fig. 4G and H).

The effects of REG3A on GC cells are dependent on PI3K/Akt and GSK3 $\beta$ signaling pathway. To uncover the molecular mechanism of REG3A in GC cells, we performed western blotting to detect PI3K/Akt related signaling pathway in REG3A overexpressed MGC-803 cells and control cells. It was found that the phosphorylation of Akt was significantly suppressed by the overexpression of REG3A (Fig. 5A). Further, we found that the phosphorylation of GSK $3 \beta$ was also suppressed by REG3A overexpression (Fig. 5B).

Further, we detected Akt-GSK3 $\beta$ signaling pathway in REG3A silenced HGC-27 cells and control cells. It was found that REG3A knockdown significantly increased the phosphorylation of Akt (Fig. 5C). Furthermore, the phosphorylation of 

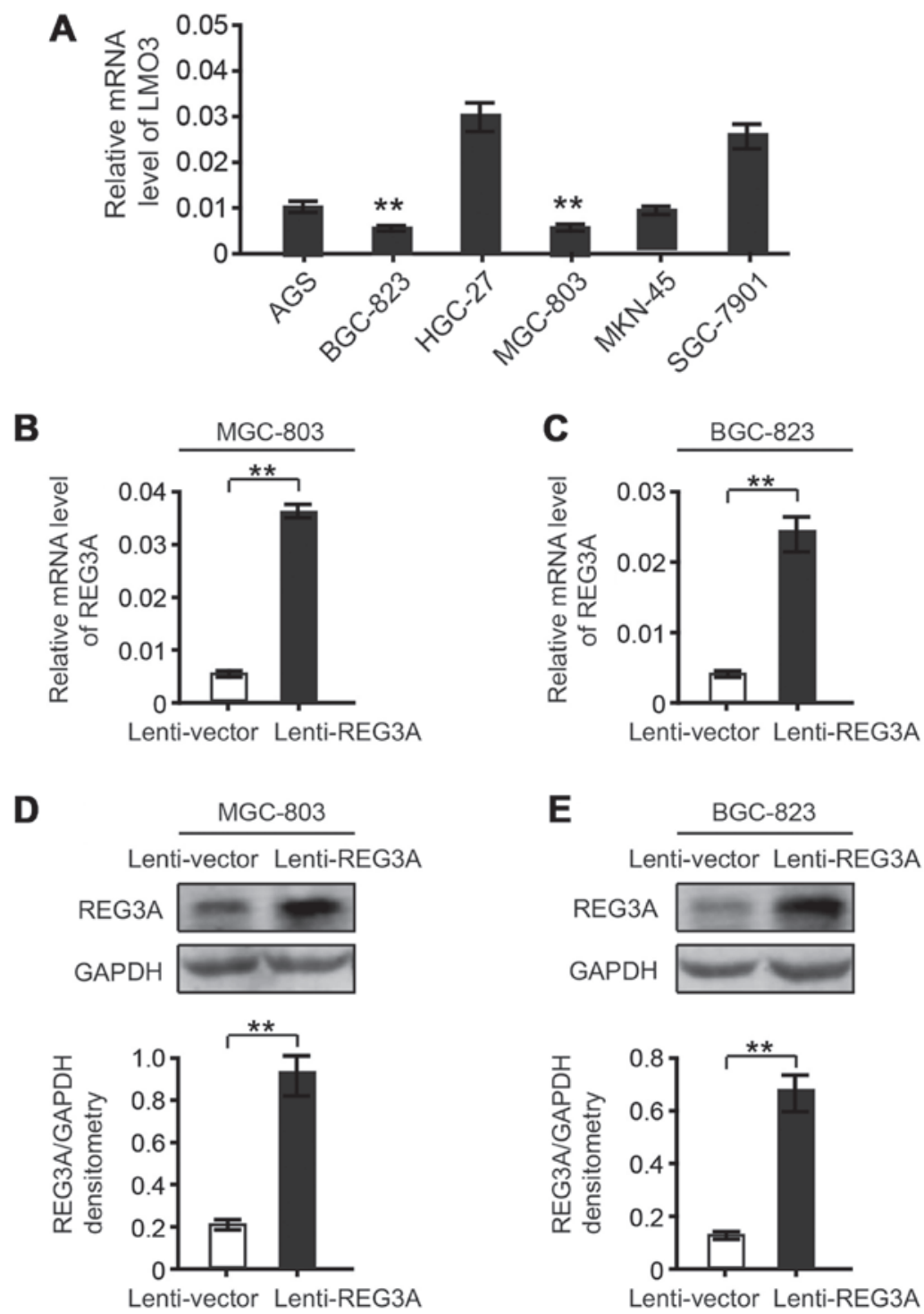

Figure 2. Overexpression of regenerating islet-derived $3 \alpha$ (REG3A) in MGC-803 and BGC-823 gastric cancer (GC) cells. (A) Expression of REG3A in GC cell lines, including AGS, BGC-823, HGC-27, MGC-803, MKN-45 and SGC-7901 cells. (B and C) The mRNA expression level of REG3A in MGC-803 (B) and BGC-823 (C) GC cells infected with lenti-vector or lenti-REG3A. (D and E) The protein expression level of REG3A in MGC-803 (D) and BGC-823 (E) GC cells infected with lenti-vector or lenti-REG3A. Statistical analysis of REG3A expression in the two groups is shown below. ${ }^{* *} \mathrm{P}<0.01$.

GSK3 $\beta$ was also increased by silencing REG3A (Fig. 5D). Then by using CHIR-98014 (the inhibitor of GSK3 $\beta$ ), it was found that CHIR-98014 could abrogate the effects of silenced REG3A on HGC-27 cells (Fig. 5E-G).

These results indicated that REG3A suppressed GC cell invasion, proliferation and promoted GC cell apoptosis dependent on Akt-GSK3 $\beta$ signaling.

\section{Discussion}

REG3A belongs to REG protein family, which includes REG1, REG3A and REG4. Previous study indicated that REG3A was downregulated in most primary human GC cells (16). However, in the last nine years no studies on REG3A in GC were reported. Its biological functions and related mechanism remain unclear. In this study, we deeply investigate the exact role of REG3A on GC. It was found that REG3A expression was obviously downregulated in GC, and high REG3A expression was associated with improved OS and DFS of patients.
Furthermore, we revealed the biological functions of REG3A in GC. We found that the invasion, proliferation and apoptosis of GC cells were regulated by REG3A. REG3A overexpression was able to suppress the invasion, and proliferation promoting apoptosis of GC cells. While REG3A knockdown had a reverse effect on the invasion, proliferation and apoptosis of GC cells.

REG3A was previously identified as a secreted protein induced by interleukin-17 (IL-17), then stimulating the proliferation and inhibiting terminal differentiation of keratinocytes during skin injury through PI3K/Akt pathway (21). It was also reported that Erk1/2 pathway lies downstream of REG signaling (22). Fibronectin 1 (FN1) was identified as a potential interaction partner for REG3A (12). FN1 stimulated the growth of non-small cell lung carcinoma cell via activating Akt signaling, and stimulated lung carcinoma cell growth via the phosphorylation of Erk $(23,24)$. Here, we demonstrated that REG3A overexpression suppressed the phosphorylation of Akt and downstream GSK3 $\beta$. While REG3A knockdown 
A

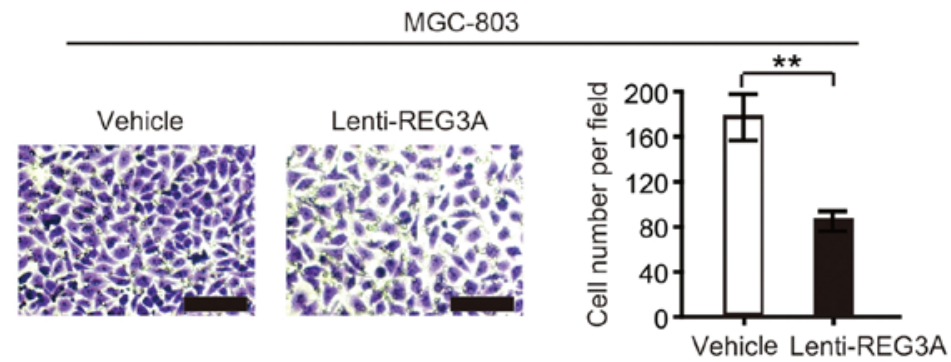

B
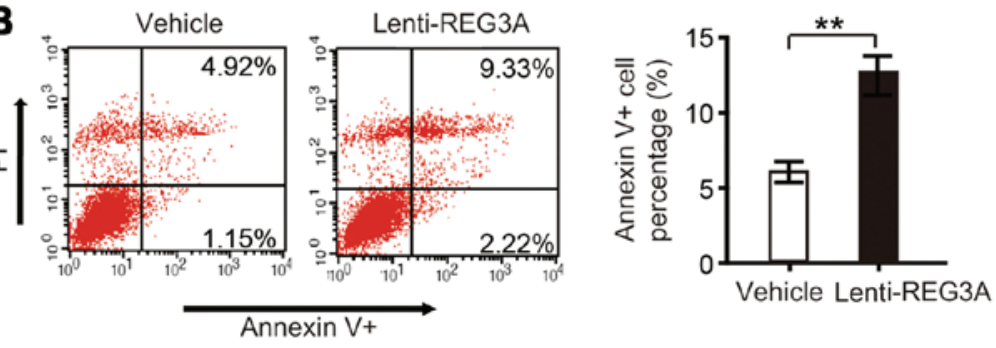

C
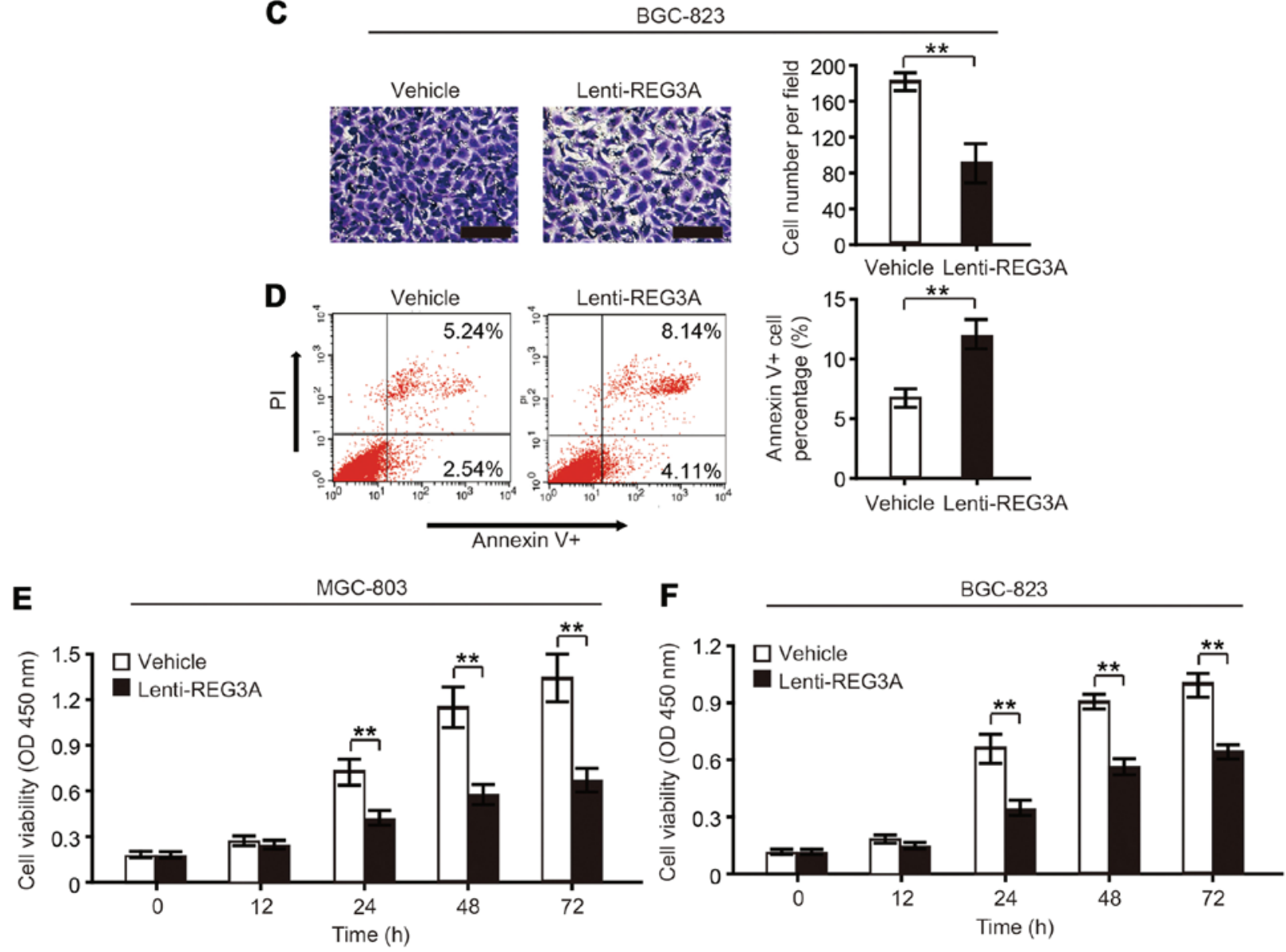

Figure 3. Regenerating islet-derived $3 \alpha$ (REG3A) overexpression suppresses invasion, and proliferation promoting apoptosis of MGC-803 and BGC-823 gastric cancer (GC) cells. (A) Representative quantification of invaded MGC-803 cells infected with lenti-vector or lenti-REG3A. Statistical analysis of invaded MGC-803 cells in the two groups is shown on the right. Scale bars, $100 \mu \mathrm{m}$. (B) Flow cytometry analysis of apoptosis of MGC-803 cells infected with lenti-vector or lenti-REG3A. Flow cytometry statistical analysis of apoptotic MGC-803 cells in the two groups is shown on the right. (C) Representative quantification of invaded BGC-823 cells infected with lenti-vector or lenti-REG3A. Statistical analysis of invaded BGC-823 cells in the two groups is shown onthe right. Scale bars, $100 \mu \mathrm{m}$. (D) Flow cytometry analysis of apoptosis of BGC-823 cells infected with lenti-vector or lenti-REG3A. Flow cytometry statistical analysis of apoptotic BGC-823 cells in the two groups is shown right. (E) Cell counting kit-8 (CCK-8) assay analysis of MGC-803 cells infected with lenti-vector or lenti-REG3A. (F) CCK-8 assay analysis of BGC-823 cells infected with lenti-vector or lenti-REG3A. ** $\mathrm{P}<0.01$.

increased the phosphorylation of Akt and GSK3 $\beta$, and the inhibitor of GSK3 $\beta$ could abrogate these effects. It was suggested that PI3K/Akt-GSK3 $\beta$ signaling played important roles in REG3A-regulated GC cells invasion, proliferation and apoptosis.
In conclusion, this study indicated that REG3A overexpression suppresses GC cells invasion, proliferation and promotes apoptosis, which are dependent on PI3K/Akt and GSK3 $\beta$ signaling pathway. REG3A may be used as a promising therapeutic strategy for GC in future. 

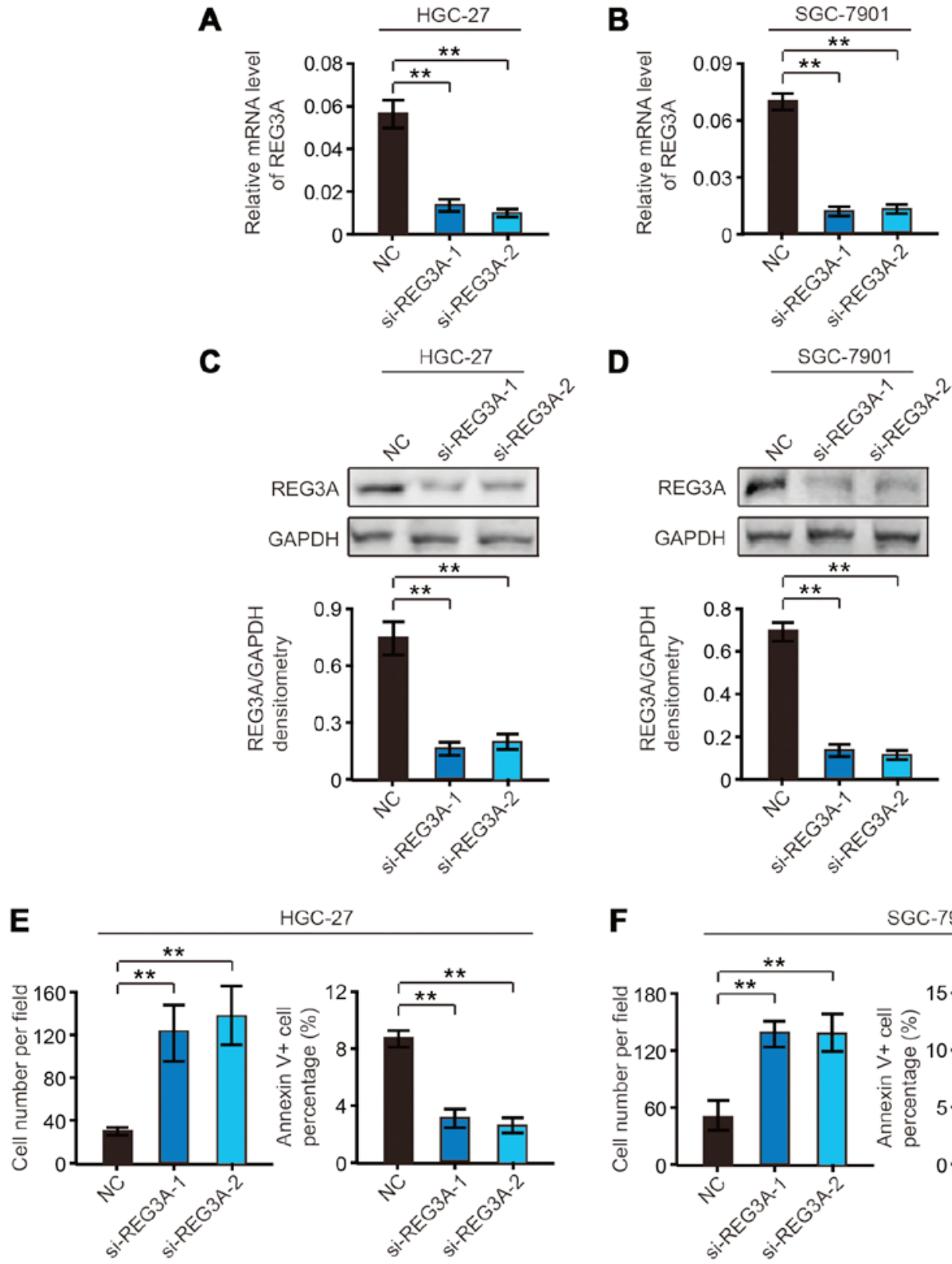

HGC-27

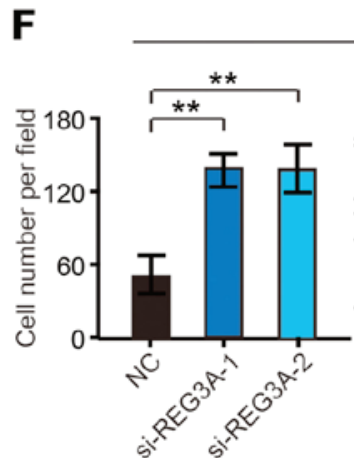

SGC-7901
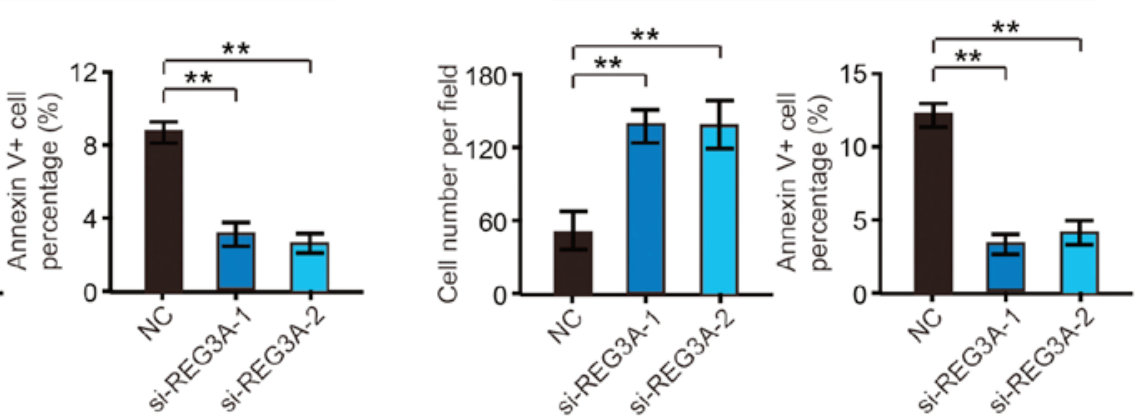

G

HGC-27

\section{H}

SGC-7901
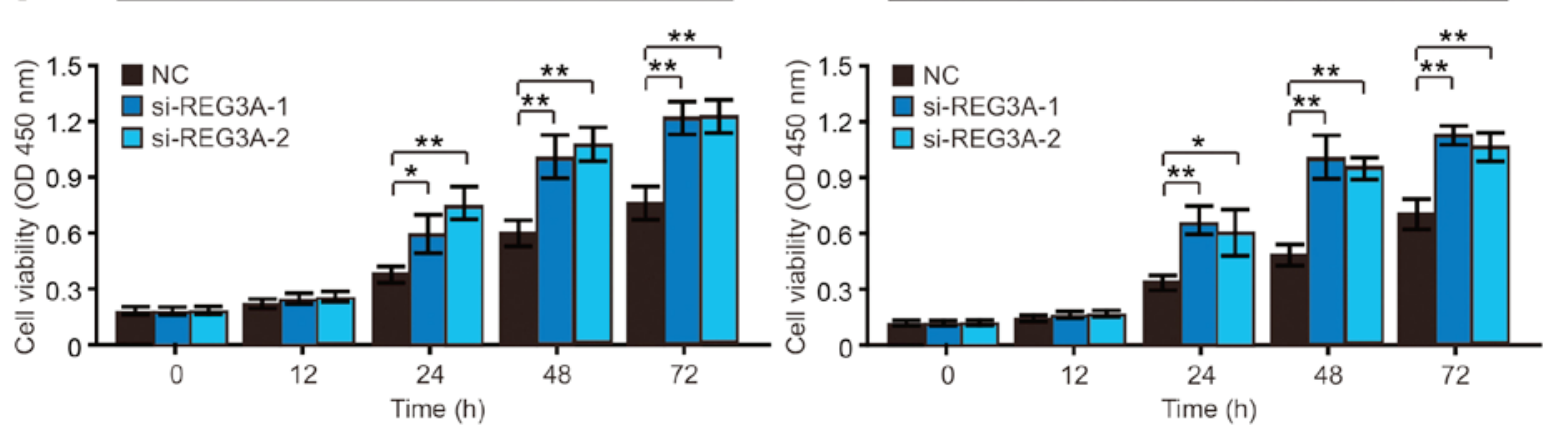

Figure 4. The regenerating islet-derived 3 $\alpha$ (REG3A) knockdown promotes invasion, and proliferation suppressing apoptosis of HGC-27 and SGC-7901 gastric cancer (GC) cells. (A and B) The mRNA expression level of REG3A in HGC-27 (B) and SGC-7901 (C) cells, which were infected with siRNA of REG3A. (C and D) The protein expression level of REG3A in HGC-27 (D) and SGC-7901 (E) cells, infected with siRNA of REG3A. Statistical analysis of REG3A expression in the two groups is shown below. (E) Representative quantification of invaded HGC-27 cells, and flow cytometry analysis of apoptotic HGC-27 cells infected with siRNA of REG3A. (F) Representative quantification of invaded SGC-7901 cells, and flow cytometry analysis of apoptotic SGC-7901 cells infected with siRNA of REG3A. (G) Cell counting kit-8 (CCK-8) assay analysis of HGC-27 cells infected with siRNA of REG3A. (H) CCK-8 assay analysis of SGC-7901 cells infected with siRNA of REG3A. ${ }^{*} \mathrm{P}<0.05$ and ${ }^{* *} \mathrm{P}<0.01$. 

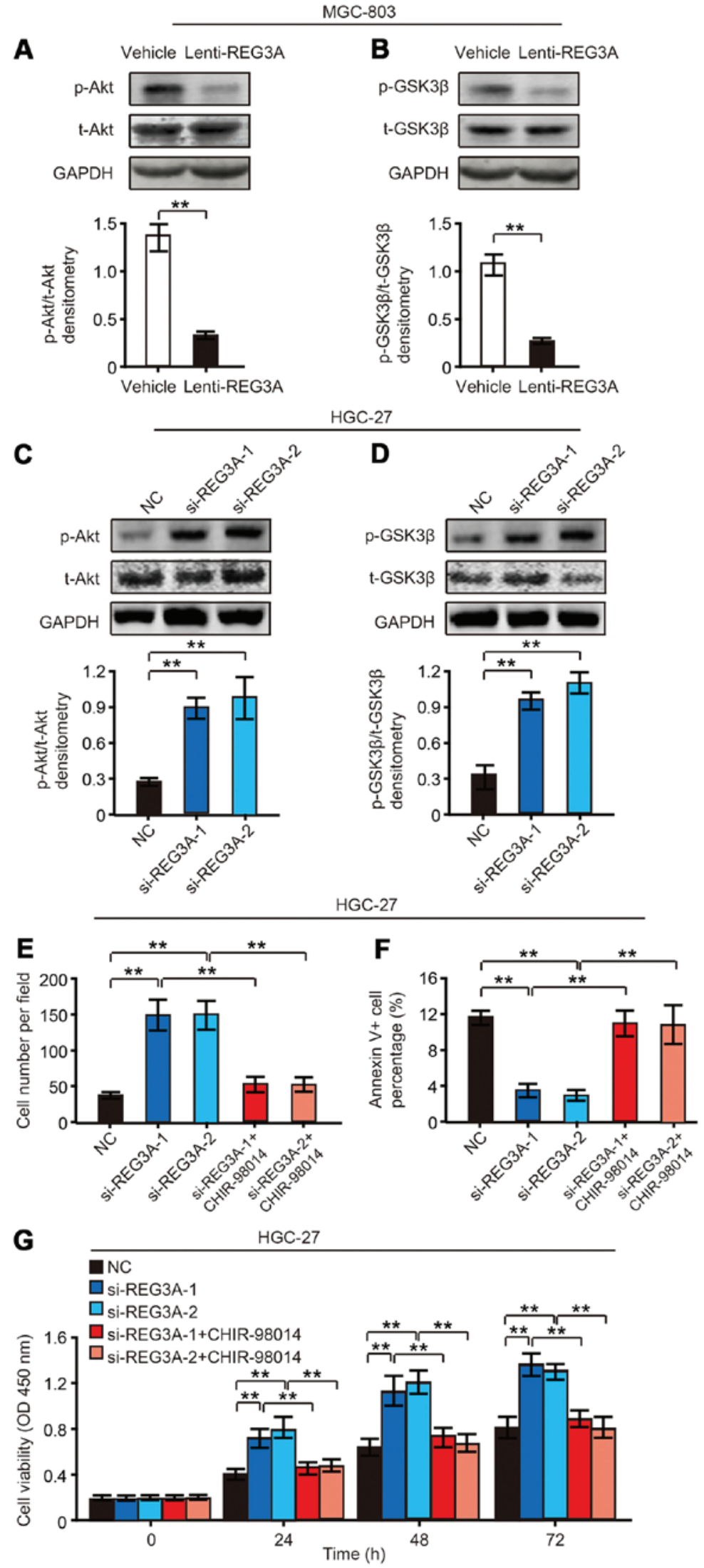

Figure 5. The regenerating islet-derived $3 \alpha$ (REG3A) regulates the phosphorylation of Akt and GSK3 $\beta$. (A) Western blotting analysis of phospho-Akt and total-Akt in REG3A overexpressed and control MGC-803 cells. Statistical analysis of phospho-Akt/total-Akt is shown below. (B) Western blotting analysis of phosphoGSK3 $\beta$ and total-GSK3 $\beta$ in REG3A overexpressed and control MGC-803 cells. Statistical analysis of phospho-GSK3 $\beta /$ total-GSK3 $\beta$ is shown below. (C) Western blot analysis of phospho-Akt and total-Akt in REG3A knockdown and control HGC-27 cells. Statistical analysis of phospho-Akt/total-Akt densitometry is shown below. (D) Western blotting analysis of phospho-GSK3 $\beta$ and total-GSK3 $\beta$ in REG3A knockdown and control HGC-27 cells. Statistical analysis of phosphoGSK3 $\beta$ /total-GSK3 $\beta$ densitometry is shown below. (E and F) REG3A knockdown HGC-27 cells were treated with 50 nM CHIR-98014 (the inhibitor of GSK3 $\beta$ ). The invaded (E) or apoptotic (F) HGC-27 cells were analyzed after 48 h. (G) REG3A knockdown HGC-27 cells were treated with 50 nM CHIR-98014 (the inhibitor of GSK3 $\beta$ ). Cell counting kit-8 (CCK-8) cell viability of HGC-27 cells were detected at $0,24,48$ and $72 \mathrm{~h}$ time-points, respectively. ${ }^{* *} \mathrm{P}<0.01$. 


\section{Acknowledgements}

The authors gratefully acknowledge the assistance of the Department of General Surgery for their help in collecting medical records.

\section{Funding}

The present study was supported by the National Natural Science Foundation of China (grant no. 81201624).

\section{Availability of data and material}

The authors declare that all of the data and material are freely available on reasonable request.

\section{Authors' contributions}

YSQ and GJL performed the experiments, analyzed the data and wrote the paper. NNJ supervised the experiments and edited the manuscript.

\section{Ethics approval and consent to participate}

All human materials were obtained following informed consent, and protocols were approved by the ethical review committee of the World Health Organization Collaborating Center for Research in Human Production.

\section{Consent for publication}

Not applicable.

\section{Competing interests}

The authors declare that they have no competing interests.

\section{Authors' information}

YSQ, Department of General Surgery, Yantai Shan Hospital, 91 Jiefang Road, Zhifu District, Yantai 264000, China; GJL and NNJ, Department of Bone Tumor, Yantai Shan Hospital, 91 Jiefang Road, Zhifu District, Yantai 264000, China, Tel: +86-535-6602001.

\section{References}

1. Wong SS, Kim KM, Ting JC, Yu K, Fu J, Liu S, Cristescu R, Nebozhyn M, Gong L, Yue YG, et al: Genomic landscape and genetic heterogeneity in gastric adenocarcinoma revealed by whole-genome sequencing. Nat Commun 5: 5477, 2014.

2. Kang G, Hwang WC, Do IG, Wang K, Kang SY, Lee J, Park SH, Park JO, Kang WK, Jang J, et al: Exome sequencing identifies early gastric carcinoma as an early stage of advanced gastric cancer. PLoS One 8: e82770, 2013.

3. Hu B, El Hajj N, Sittler S, Lammert N, Barnes R and Meloni-Ehrig A: Gastric cancer: Classification, histology and application of molecular pathology. J Gastrointest Oncol 3: 251-261, 2012.

4. Zang ZJ, Cutcutache I, Poon SL, Zhang SL, McPherson JR, Tao J, Rajasegaran V, Heng HL, Deng N, Gan A, et al: Exome sequencing of gastric adenocarcinoma identifies recurrent somatic mutations in cell adhesion and chromatin remodeling genes. Nat Genet 44: 570-574, 2012.
5. Bass AJ, Thorsson V, Shmulevich I, Reynolds SM, Miller M, Bernard B, Hinoue T, Laird PW, Curtis C, Shen H, et al; Cancer Genome Atlas Research Network: Comprehensive molecular characterization of gastric adenocarcinoma. Nature 513: 202-209, 2014.

6. Ding Y, Yang Q, Wang B, Ye G and Tong X: The correlation of MGMT promoter methylation and clinicopathological features in gastric cancer: A systematic review and meta-analysis. PLoS One 11: e0165509, 2016.

7. Baroudi $\mathrm{O}$ and Benammar-Elgaaied A: Involvement of genetic factors and lifestyle on the occurrence of colorectal and gastric cancer. Crit Rev Oncol Hematol 107: 72-81, 2016.

8. Zhou J, Shen J, Seifer BJ, Jiang S, Wang J, Xiong H, Xie L, Wang L and Sui X: Approaches and genetic determinants in predicting response to neoadjuvant chemotherapy in locally advanced gastric cancer. Oncotarget 8: 30477-30494, 2017.

9. Qi J, Zhang P, Wang Y, Chen H and Li Y: Does total gastrectomy provide better outcomes than distal subtotal gastrectomy for distal gastric cancer? A systematic review and meta-analysis. PLoS One 11: e0165179, 2016.

10. Lasserre C, Christa L, Simon MT, Vernier P and Bréchot C: A novel gene (HIP) activated in human primary liver cancer. Cancer Res 52: 5089-5095, 1992.

11. Dusetti NJ, Frigerio JM, Fox MF, Swallow DM, Dagorn JC and Iovanna JL: Molecular cloning, genomic organization, and chromosomal localization of the human pancreatitis-associated protein (PAP) gene. Genomics 19: 108-114, 1994

12. Christa L, Carnot F, Simon MT, Levavasseur F, Stinnakre MG, Lasserre C, Thepot D, Clement B, Devinoy E and Brechot C: HIP/ PAP is an adhesive protein expressed in hepatocarcinoma, normal Paneth, and pancreatic cells. Am J Physiol 271: G993-G1002, 1996.

13. Liu JL, Cui W, Li B and Lu Y: Possible roles of reg family proteins in pancreatic islet cell growth. Endocr Metab Immune Disord Drug Targets 8: 1-10, 2008.

14. Li L, Bachem MG, Zhou S, Sun Z, Chen J, Siech M, Bimmler D and Graf R: Pancreatitis-associated protein inhibits human pancreatic stellate cell MMP-1 and -2, TIMP-1 and -2 secretion and RECK expression. Pancreatology 9: 99-110, 2009.

15. Lieu HT, Batteux F, Simon MT, Cortes A, Nicco C, Zavala F, Pauloin A, Tralhao JG, Soubrane O, Weill B, et al: HIP/PAP accelerates liver regeneration and protects against acetaminophen injury in mice. Hepatology 42: 618-626, 2005.

16. Choi B, Suh Y, Kim WH, Christa L, Park J and Bae CD: Downregulation of regenerating islet-derived 3 alpha (REG3A) in primary human gastric adenocarcinomas. Exp Mol Med 39: 796-804, 2007.

17. Xu Q, Fu R, Yin G, Liu X, Liu Y and Xiang M: Microarray-based gene expression profiling reveals genes and pathways involved in the oncogenic function of REG3A on pancreatic cancer cells. Gene 578: 263-273, 2016.

18. Liu X, Wang J, Wang H, Yin G, Liu Y,Lei X and Xiang M: REG3A accelerates pancreatic cancer cell growth under IL-6-associated inflammatory condition: Involvement of a REG3A-JAK2/STAT3 positive feedback loop. Cancer Lett 362: 45-60, 2015.

19. Wang J, Zhou H, Han Y, Liu X, Wang M, Wang X, Yin G, Li X and Xiang M: SOCS3 methylation in synergy with Reg3A overexpression promotes cell growth in pancreatic cancer. J Mol Med (Berl) 92: 1257-1269, 2014.

20. Ye Y, Xiao L, Wang SJ, Yue W, Yin QS, Sun MY, Xia W, Shao ZY and Zhang H: Up-regulation of REG3A in colorectal cancer cells confers proliferation and correlates with colorectal cancer risk. Oncotarget 7: 3921-3933, 2016

21. Lai Y, Li D, Li C, Muehleisen B, Radek KA, Park HJ, Jiang Z, Li Z, Lei H, Quan Y, et al: The antimicrobial protein REG3A regulates keratinocyte proliferation and differentiation after skin injury. Immunity 37: 74-84, 2012.

22. Kadowaki Y, Ishihara S, Miyaoka Y, Rumi MA, Sato H, Kazumori H, Adachi K, Takasawa S, Okamoto H, Chiba T, et al: Reg protein is overexpressed in gastric cancer cells, where it activates a signal transduction pathway that converges on ERK1/2 to stimulate growth. FEBS Lett 530: 59-64, 2002.

23. Han S, Khuri FR and Roman J: Fibronectin stimulates non-small cell lung carcinoma cell growth through activation of $\mathrm{Akt} / \mathrm{mammalian}$ target of rapamycin/S6 kinase and inactivation of LKB1/AMP-activated protein kinase signal pathways. Cancer Res 66: 315-323, 2006.

24. Han S, Sidell N and Roman J: Fibronectin stimulates human lung carcinoma cell proliferation by suppressing p 21 gene expression via signals involving Erk and Rho kinase. Cancer Lett 219: 71-81, 2005.

This work is licensed under a Creative Commons Attribution-NonCommercial-NoDerivatives 4.0 International (CC BY-NC-ND 4.0) License. 